\title{
Biochemical and immunological comparison of lipopolysaccharides from Bordetella species
}

\author{
Ken-Ichi Amano, ${ }^{1 *} \nmid$ Kazue Fuxushi $^{1}$ and Mitsuru Watanabe ${ }^{2}$ \\ ${ }^{1}$ Department of Bacteriology, Hirosaki University School of Medicine, Hirosaki, Aomori 036, Japan \\ ${ }^{2}$ The Kitasato Institute, Shirokane, Minato-ku, Tokyo 108, Japan
}

(Received 25 July 1989; revised 30 October 1989; accepted 28 November 1989)

\begin{abstract}
Lipopolysaccharides (LPS) isolated from Bordetella pertussis, B. parapertussis and B. bronchiseptica were analysed for their chemical composition, molecular heterogeneity and immunological properties. All the LPS preparations contained heptose, 3-deoxy-D-manno-2-octulosonic acid, glucosamine, uronic acid, phosphate and fatty acids. The fatty acids C14:0, C16:0 and $\beta O H C 14: 0$ were common to all the LPS preparations. LPS from $B$. pertussis strains additionally contained isoC16:0, those from $B$. parapertussis contained isoC14:0 and isoC16:0, and those from $B$. bronchiseptica contained C16:1. By SDS-PAGE, LPS from $B$. pertussis had two bands of low molecular mass, and the LPS from $B$. parapertussis and $B$. bronchiseptica showed low molecular mass bands together with a ladder arrangement of high molecular mass bands. Immunodiffusion, quantitative agglutination and ELISA demonstrated that the LPS from $B$. pertussis strains reacted with antisera prepared against whole cells of $B$. pertussis and $B$. bronchiseptica; LPS from $B$. parapertussis reacted with antisera to $B$. parapertussis and $B$. bronchiseptica, and LPS from $B$. bronchiseptica reacted with anti-whole cell serum raised against any of the three species. From these results, it is concluded that LPS from $B$. bronchiseptica has structures in common with LPS from $B$. pertussis and $B$. parapertussis, while the LPS from $B$. pertussis and $B$. parapertussis are serologically entirely different from each other.
\end{abstract}

\section{Introduction}

Lipopolysaccharide (LPS) of Bordetella pertussis has toxic activities similar to those of LPS from other Gramnegative bacteria (Finger et al., 1976; MacLennan, 1960; Nakase et al., 1970). In addition, LPS from B. pertussis sensitizes mice to histamine (Bergman \& Munoz, 1977) and affects the lymphocytosis induced by pertussis toxin (Kurokawa et al., 1978).

LPS from $B$. pertussis contain lipid $A$ and an oligosaccharide core having 3-deoxy-D-manno-2-octulosonic acid (KDO) (Moreau et al., 1984), but they do not contain the long-chain polysaccharide characteristic of the LPS of enterobacteria (Hitchcock et al., 1986). Peppler (1984) reported that SDS-PAGE profiles of LPS from $B$. pertussis showed two bands by silver staining

$\dagger$ Present address: Central Research Laboratory, Akita University School of Medicine, Akita 010, Japan.

Abbreviations: LPS, lipopolysaccharide(s); KDO, 3-deoxy-D-manno2-octulosonic acid; GlcN, glucosamine; GlcN-P, phosphoryl glucosamine. which were similar to those given by R-type LPS from enterobacteria. LeDur et al. (1980) also described the presence of two chemically and immunologically distinct LPS in B. pertussis of different serological type. Very little is known about the LPS of $B$. parapertussis and $B$. bronchiseptica.

In the present work, we compared the chemical composition and SDS-PAGE profiles of LPS extracted from different phases of $B$. pertussis, and from the other two species of Bordetella, and compared the antigenicity of these LPS preparations by quantitative agglutination, immunodiffusion and ELISA.

\section{Methods}

Organisms and growth conditions. The following strains were used: $\boldsymbol{B}$. pertussis Tohama [phase I, BpI(TOHAMA)], 18-323 [phase I, BpI(18323)], Sakairi [phase III, BpIII(SAKAIRI)] and UV-1570 [phase III, BpIII(UV-1570)]; one strain of B. parapertussis [Bpp(21815)]; and two strains of $B$. bronchiseptica $[\mathrm{Bbs}(\mathrm{L} 3)$ and $\mathrm{Bbs}(\mathrm{H}-214)]$. All of these cultures were obtained from our laboratory stock. B. pertussis strain AK-168 [BpI(AK-168)] and B. parapertussis strain AK-167 [Bpp(AK167)] were isolated from the same patient (Watanabe et al., 1987). 
All strains were grown in the synthetic liquid medium of Stainer \& Scholte (1971), with shaking for $24-48 \mathrm{~h}$ at $36^{\circ} \mathrm{C}$. The cells were collected by centrifugation at $6000 \mathrm{~g}$ for $20 \mathrm{~min}$, killed with $0.5 \%$ formaldehyde, and lyophilized.

Preparation of LPS. LPS was extracted from formaldehyde-treated whole cells by the hot phenol/water method of Westphal \& Jann (1965). The extract was centrifuged at $100000 \mathrm{~g}$ for $2 \mathrm{~h}$, and the sediment was washed twice with distilled water and lyophilized (designated crude LPS). This crude LPS $(20 \mathrm{mg}$ ) was treated with $1 \mathrm{mg}$ DNAase I (Sigma) and $1 \mathrm{mg}$ of RNAase A (Sigma) overnight at $37^{\circ} \mathrm{C}$. Trypsin (Sigma, $2 \mathrm{mg}$ ) was then added and the mixture incubated for $1 \mathrm{~d}$ at $37^{\circ} \mathrm{C}$. The mixture was also treated with $2 \mathrm{mg}$ proteinase $\mathrm{K}$ (Merck) at $37^{\circ} \mathrm{C}$ for an additional $1 \mathrm{~d}$. Finally, the mixture was centrifuged at $100000 \mathrm{~g}$ for $2 \mathrm{~h}$ or at $150000 \mathrm{~g}$ for $4 \mathrm{~h}$, then the sediment was washed twice, and lyophilized. The product was called 'purified LPS'. Purified LPS from each strain was used in this work, except for the preparation from BpI(тонама), which was crude LPS.

Analytical methods. The following assay methods were used: neutral sugars were assayed by the phenol/sulphuric acid method (Dubois et al., 1956) with glucose as a reference standard; heptose was analysed by the cysteine/sulphuric acid method (Osborn, 1963) with glycero-Dglucoheptose (Sigma) as a reference; KDO was determined by the thiobarbituric acid method of Karkhanis et al. (1978) with a small modification ( $2 \mathrm{M}-\mathrm{HCl}$ hydrolysis for $90 \mathrm{~min}$ instead of $0.05 \mathrm{M}-\mathrm{H}_{2} \mathrm{SO}_{4}$ hydrolysis for $30 \mathrm{~min}$ ) with KDO (Sigma) as a reference; protein was assayed by the Lowry method; total phosphorus was determined by the method of Lowry et al. (1954); amino acids and amino compounds, including amino sugars, were analysed in a K202 amino acid autoanalyser (Kyowa Seimitzu Co.) after hydrolysis for $4 \mathrm{~h}$ in $4 \mathrm{M}-\mathrm{HCl}$ at $100{ }^{\circ} \mathrm{C}$ in sealed ampoules (Amano et al., 1987); fatty acids were analysed as methyl esters in a Hitachi 163 gas chromatograph on a Chromosorb WAW column containing $15 \%$ ethylene glycol succinate (Gasukuro Kogyo Co.) as described previously (Amano et al., 1984). Identification and quantitative analysis of neutral sugars were done in a Hitachi 163 gas chromatograph with the sugars as alditol acetates on a $3 \%$ ECNSS-M Gas-Chrom Q glass column (Gasukuro Kogyo Co.) as described previously (Amano \& Williams, 1984), and as trimethylsilyl derivatives on a $2.5 \%$ SE-30 Chromosorb WAW column (Gasukuro Kogyo Co.).

SDS-PAGE. The technique of Laemmli (1970) was used, with the following modifications. The $1.0 \mathrm{~mm}$ thick slab gel contained $17.5 \%$ (w/v) polyacrylamide, and the spacer gel $5 \%$. Each sample $(2-8 \mu \mathrm{g})$ was boiled for $5 \mathrm{~min}$ in Laemmli sample buffer and applied to each slot. The gels were stained with silver as described previously (Amano et al., 1987).

Immunization. New Zealand White rabbits weighing 1.9-2.2 kg were pre-bled and given weekly intravenous doses of $1 \mathrm{mg}$ formaldehydetreated, lyophilized whole cells suspended in $0.4 \mathrm{ml}$ distilled water. A total of four injections was given and the rabbits were bled $7 \mathrm{~d}$ after the fourth injection. The sera were separated by centrifugation.

Serological methods. Immunodiffusion assays were done in $1 \%(\mathrm{w} / \mathrm{v})$ agarose gels according to the method of Ouchterlony (1958). A tube agglutination test (Nichols \& Nakamura, 1980) and ELISA (Kasai et $a l ., 1986)$ were performed to determine serogroup antigen specificity.

\section{Results}

\section{Isolation and chemical analysis of Bordetella LPS}

The LPS preparations of the Bordetella species, except that of BpI(TOHAMA), were strongly associated with
Table 1. Chemical composition of LPS preparations from Bordetella species

Except for protein content, the results are expressed as molar ratios relative to heptose (taken as 1.0 ). The analyses were repeated 3 times for each strain; mean values are shown.

\begin{tabular}{|c|c|c|c|c|c|c|}
\hline LPS from & $\begin{array}{l}\text { Total } \\
\text { GlcN }\end{array}$ & $\begin{array}{l}\text { Neutral } \\
\text { sugar* }\end{array}$ & $\begin{array}{c}\text { Uronic } \\
\text { acid } \dagger\end{array}$ & KDO & $\begin{array}{c}\text { Total } \\
\text { phosphorus }\end{array}$ & $\begin{array}{c}\text { Protein } \\
(\%, w / w)\end{array}$ \\
\hline ВрI(ТОНАМА) & $2 \cdot 2$ & 1.0 & 0.5 & $0 \cdot 6$ & 1.9 & trace \\
\hline BpI(AK-168) & 2.9 & 1.9 & $0 \cdot 6$ & $0 \cdot 5$ & $5 \cdot 6$ & $7 \cdot 5$ \\
\hline BpI(18-323) & 1.5 & 0.5 & 0.7 & 0.7 & 2.9 & trace \\
\hline BPIII(SAKAIRI) & $2 \cdot 5$ & $1 \cdot 5$ & 0.7 & 0.5 & $5 \cdot 0$ & $7 \cdot 1$ \\
\hline BpIII(UV-1570) & $2 \cdot 8$ & 0.6 & 0.6 & 0.7 & $2 \cdot 3$ & $6 \cdot 4$ \\
\hline $\mathrm{Bpp}(21815)$ & $4 \cdot 2$ & 0.5 & 0.7 & $0 \cdot 7$ & $4 \cdot 0$ & 1.8 \\
\hline Bpp(AK-167) & $4 \cdot 0$ & 0.6 & $0 \cdot 7$ & $0 \cdot 6$ & $3 \cdot 8$ & $2 \cdot 1$ \\
\hline $\operatorname{Bbs}(\mathbf{L} 3)$ & $3 \cdot 5$ & 1.0 & $0 \cdot 1$ & $0 \cdot 7$ & $3 \cdot 7$ & $2 \cdot 4$ \\
\hline $\mathrm{Bbs}(\mathrm{H}-214)$ & $4 \cdot 6$ & $1 \cdot 7$ & 0.9 & 0.6 & $3 \cdot 6$ & $2 \cdot 4$ \\
\hline
\end{tabular}

* Neutral sugar minus heptose and uronic acid.

† Uronic acid minus heptose.

outer-membrane proteins; after ultracentrifugation they still consisted of $7 \cdot 3-59.9 \%(\mathrm{w} / \mathrm{w})$ protein as determined by the Lowry method (data not shown). After treatment with proteolytic enzymes (trypsin and proteinase $\mathrm{K}$ ), the protein content decreased (trace to $7.5 \%$ ) but was not completely removed (Table 1). Only the LPS from BpI(тонама) was freed from the proteins by ultracentrifugation. Since after the enzyme treatments the LPS of $B$. parapertussis and $B$. bronchiseptica could not be precipitated by ultracentrifugation at $100000 \mathrm{~g}$ for $2 \mathrm{~h}$, these preparations were sedimented at $150000 \mathrm{~g}$ for $4 \mathrm{~h}$.

The molar ratios, relative to heptose, of total glucosamine [GlcN, including free GlcN and phosphorylated GlcN (GlcN-P), both detected by the amino acid analyser after acid hydrolysis], neutral sugar, uronic acid, KDO and total phosphorus in five LPS preparations from $B$. pertussis strains were different (Table 1). The molar ratios of the components described above in two preparations of LPS from $B$. parapertussis were very similar $[4 \cdot 2: 0 \cdot 5: 0 \cdot 7: 0 \cdot 7: 4 \cdot 0$ for LPS from $B p p(21815)$ and $4 \cdot 0: 0 \cdot 6: 0 \cdot 7: 0 \cdot 6: 3 \cdot 8$ for LPS Bpp(AK-167)], while those in the two $B$. bronchiseptica preparations were different from each other $[3 \cdot 5: 1 \cdot 0: 0 \cdot 1: 0 \cdot 7: 3 \cdot 7$ for LPS from $B b s(L 3)$ and $4 \cdot 6: 1 \cdot 7: 0 \cdot 9: 0 \cdot 6: 3 \cdot 6$ for LPS from $\operatorname{Bbs}(\mathrm{H}-214)]$. The molar ratios of total GlcN to heptose in LPS from $B$. parapertussis and $B$. bronchiseptica were slightly higher than those from $B$. pertussis. The other ratios were not significantly different in the various LPS preparations.

Table 2 shows the fatty acid composition of the LPS preparations. Five LPS preparations from $B$. pertussis and two from $B$. parapertussis contained isoC16:0 in addition to $\mathrm{C} 14: 0, \mathrm{C16}: 0$ and $\beta \mathrm{OHC14:0}$ ( $\beta$-hydroxy- 
Table 2. Fatty acid composition of LPS preparations from Bordetella species

The results are expressed as percentages $(w / w)$ of total fatty acids. The analyses were repeated 3 times for each strain; average values are shown.

\begin{tabular}{lccccccccc}
\hline \hline Fatty acid & $\begin{array}{c}\text { BpI } \\
\text { (TOHAMA) }\end{array}$ & $\begin{array}{c}\text { BpI } \\
(\text { AK-168) }\end{array}$ & $\begin{array}{c}\text { BpI } \\
(18-323)\end{array}$ & $\begin{array}{c}\text { BpIII } \\
\text { (SAKAIRI) }\end{array}$ & $\begin{array}{c}\text { BpIII } \\
(\text { UV-1570) }\end{array}$ & $\begin{array}{c}\text { Bpp } \\
(21815)\end{array}$ & $\begin{array}{c}\text { Bpp } \\
\text { (AK-167) }\end{array}$ & $\begin{array}{c}\text { Bbs } \\
(\text { L3) }\end{array}$ & $\begin{array}{c}\text { Bbs } \\
(\text { H-214) }\end{array}$ \\
\hline C12:0 & - & - & - & - & - & - & - & - & $4 \cdot 6$ \\
isoC14:0 & - & - & - & - & - & $2 \cdot 8$ & $3 \cdot 4$ & - & $3 \cdot 1$ \\
C14:0 & $28 \cdot 5$ & $29 \cdot 3$ & $27 \cdot 6$ & $21 \cdot 0$ & $29 \cdot 7$ & $27 \cdot 3$ & $20 \cdot 3$ & $18 \cdot 8$ & $32 \cdot 9$ \\
isoC16:0 & $20 \cdot 6$ & $6 \cdot 0$ & $23 \cdot 1$ & $7 \cdot 2$ & $17 \cdot 2$ & $12 \cdot 7$ & $13 \cdot 4$ & - & - \\
C16:0 & $7 \cdot 2$ & $14 \cdot 2$ & $13 \cdot 5$ & $7 \cdot 4$ & $7 \cdot 2$ & $26 \cdot 8$ & $37 \cdot 2$ & $21 \cdot 8$ & $10 \cdot 1$ \\
C16:1 & - & - & $7 \cdot 0$ & - & - & - & - & $12 \cdot 8$ & $12 \cdot 0$ \\
isoC18:0 & - & - & $7 \cdot 3$ & - & $9 \cdot 9$ & - & - & - & - \\
C18:0 & - & $4 \cdot 5$ & $3 \cdot 3$ & - & $1 \cdot 2$ & $2 \cdot 4$ & - & $2 \cdot 4$ & - \\
$\beta$ OHC14:0 & $42 \cdot 9$ & $46 \cdot 2$ & $15 \cdot 0$ & 64.5 & $34 \cdot 7$ & $28 \cdot 1$ & $25 \cdot 8$ & $42 \cdot 6$ & $37 \cdot 8$ \\
\hline \hline
\end{tabular}

-. Not detected.

Table 3. Amino acid and amino sugar composition of LPS preparations from Bordetella species

The results are expressed as molar ratios relative to heptose (taken as 1.0 ). The analyses were repeated 3 times for each strain; average values are shown.

\begin{tabular}{|c|c|c|c|c|c|c|c|c|c|}
\hline $\begin{array}{l}\text { Amino acid or } \\
\text { amino sugar }\end{array}$ & $\begin{array}{c}\text { BpI } \\
\text { (TOHAMA) }\end{array}$ & $\begin{array}{c}\text { BpI } \\
(\mathrm{AK}-168)\end{array}$ & $\begin{array}{c}\text { BpI } \\
(18-323)\end{array}$ & $\begin{array}{c}\text { BpIII } \\
\text { (SAKAIRI) }\end{array}$ & $\begin{array}{c}\text { BpIII } \\
(\text { UV-1570) }\end{array}$ & $\begin{array}{c}\text { Bpp } \\
(21815)\end{array}$ & $\begin{array}{c}\text { Bpp } \\
(\mathrm{AK}-167)\end{array}$ & $\begin{array}{l}\text { Bbs } \\
\text { (L3) }\end{array}$ & $\begin{array}{c}\text { Bbs } \\
(\mathrm{H}-214)\end{array}$ \\
\hline Asp & - & 0.1 & - & $0 \cdot 1$ & $0 \cdot 2$ & $0 \cdot 1$ & $0 \cdot 1$ & - & $0 \cdot 1$ \\
\hline Ser & - & 0.4 & - & 0.3 & $0 \cdot 2$ & - & $0 \cdot 1$ & - & $0 \cdot 1$ \\
\hline Glu & - & 0.6 & - & 0.5 & 0.4 & - & $0 \cdot 1$ & $0 \cdot 1$ & $0 \cdot 1$ \\
\hline Gly & - & $0 \cdot 2$ & - & $0 \cdot 1$ & $0 \cdot 3$ & $0 \cdot 1$ & 0.1 & - & $0 \cdot 1$ \\
\hline Ala & - & $1 \cdot 1$ & - & 0.9 & $0 \cdot 8$ & $0 \cdot 1$ & $0 \cdot 2$ & $0 \cdot 1$ & $0 \cdot 2$ \\
\hline Leu & - & 0.6 & - & 0.5 & $0 \cdot 4$ & - & $0 \cdot 1$ & $0 \cdot 1$ & $0 \cdot 1$ \\
\hline Phe & - & $0 \cdot 4$ & - & $0 \cdot 3$ & $0 \cdot 2$ & - & - & - & $0 \cdot 1$ \\
\hline Arg & - & $0 \cdot 1$ & - & $0 \cdot 1$ & $0 \cdot 1$ & - & $0 \cdot 1$ & - & $0 \cdot 1$ \\
\hline GlcN & 1.4 & $2 \cdot 2$ & 0.9 & 1.9 & 1.7 & $2 \cdot 3$ & $2 \cdot 2$ & $2 \cdot 1$ & $3 \cdot 4$ \\
\hline GlcN-P & 0.8 & 0.7 & $0 \cdot 6$ & $0 \cdot 6$ & $1 \cdot 1$ & 1.9 & 1.8 & $1 \cdot 3$ & $1 \cdot 1$ \\
\hline
\end{tabular}

-, Not detected.

myristic acid) as major fatty acid components, while two LPS preparations from $B$. bronchiseptica contained $\mathrm{C} 14: 0, \mathrm{C} 16: 0, \mathrm{C} 16: 1$ and $\beta \mathrm{OHC14}: 0$, without isoC16:0. The data show that isoC16:0 is specific to $B$. pertussis and $B$. parapertussis LPS, and C16:1 is specific to $B$. bronchiseptica LPS.

Mannoheptose was the only neutral sugar detected in LPS from $B$. pertussis and $B$. bronchiseptica by gas chromatographic analysis of alditol acetate derivatives; it was not detected in LPS from B. parapertussis (data not shown). The same results were obtained when LPS acid hydrolysates were trimethylsilylated and analysed by gas chromatography (data not shown).

\section{Amino acid and amino compound compositions of LPS}

All the LPS preparations contained GlcN and GlcN-P, which are constituents of the lipid A of LPS from enterobacteria (Table 3). Further, LPS from the $B$. pertussis strains, except BpI(TOHAMA) and BpI(18-323), contained all the amino acids listed in Table 3 , and the LPS from B. parapertussis and B. bronchiseptica contained mainly aspartic acid, serine, glutamic acid, glycine, alanine, leucine and arginine, probably originating from the hydrophobic outer-membrane proteins.

\section{Comparison of LPS by SDS-PAGE}

The molecular size and microheterogeneity of LPS from Bordetella were compared by SDS-PAGE (Fig. 1). The patterns of five preparations from $B$. pertussis were composed of two low molecular mass bands in different ratios. The apparent molecular masses of the slow- and fast-migrating bands were 4.5 and $3.4 \mathrm{kDa}$, respectively. The $3.4 \mathrm{kDa}$ band was present in low concentrations in LPS from B. pertussis (Fig. 1, lanes 1, 2, 4 and 5) with the 


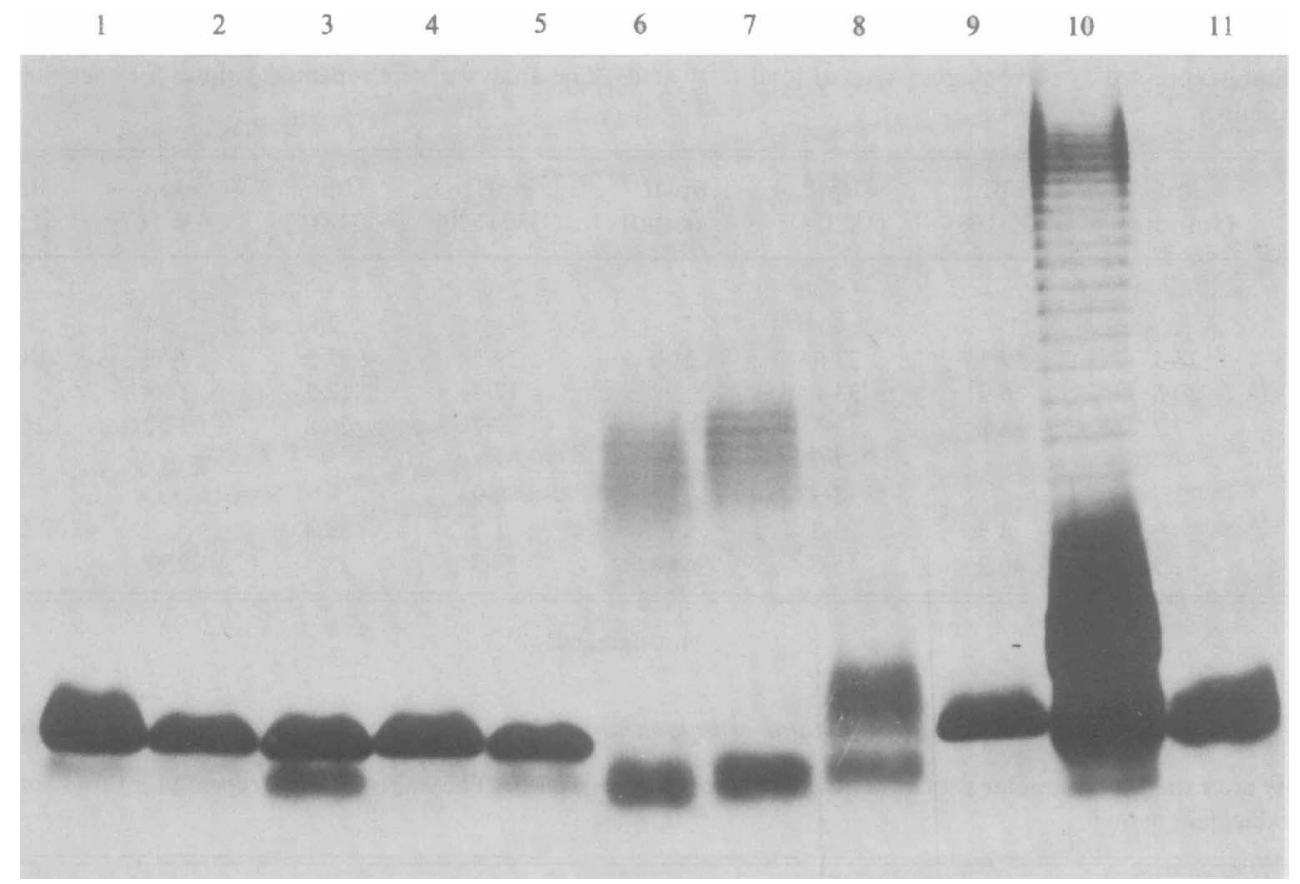

Fig. 1. Comparison of LPS preparations from Bordetella species and Salmonella minnesota by SDS-PAGE using $17.5 \%$ polyacrylamide gel. After electrophoresis the gel was stained with silver. Lanes: 1, BpI(TOHAMA); 2, BpI(AK-168); 3, BpI(18-323); 4, BpIII(SAKAIRI); 5 , BpIII(UV-1570); 6, Bpp(21815); 7, Bpp(AK-167); 8, Bbs(L3); 9, Bbs(H-214); 10, S. minnesota wild-type LPS; 11, S. minnesota Ramutant LPS.

Table 4. ELISA titres against LPS employing rabbit antisera against whole cells of Bordetella The tests were repeated twice and representative results are shown.

\begin{tabular}{lcccccccrr}
\hline \hline & \multicolumn{7}{c}{ ELISA titre using polyclonal antibody against whole cells of: } \\
\cline { 2 - 10 } \multicolumn{1}{c}{ LPS from* } & $\begin{array}{c}\text { BpI } \\
\text { (TOHAMA) }\end{array}$ & $\begin{array}{c}\text { BpI } \\
\text { (AK-168) }\end{array}$ & $\begin{array}{c}\text { BpI } \\
(18-323)\end{array}$ & $\begin{array}{c}\text { BpIII } \\
\text { (SAKAIRI) }\end{array}$ & $\begin{array}{c}\text { BpIII } \\
\text { (UV-1570) }\end{array}$ & $\begin{array}{c}\text { Bpp } \\
(21815)\end{array}$ & $\begin{array}{c}\text { Bpp } \\
\text { (AK-167) }\end{array}$ & $\begin{array}{c}\text { Bbs } \\
\text { (L3) }\end{array}$ & $\begin{array}{c}\text { Bbs } \\
(\text { H-214) }\end{array}$ \\
\hline BpI(TOHAMA) & 75010 & 7540 & 3970 & 11350 & 58260 & $<100$ & $<100$ & 6080 & 49050 \\
BpI(AK-168) & 24460 & 3490 & 220 & 5600 & 52680 & $<100$ & $<100$ & 2600 & 17070 \\
BpI(18-323) & 8700 & 1400 & 200 & 3950 & 11030 & $<100$ & $<100$ & 2040 & 5460 \\
BpIII(SAKAIRI) & 43170 & 4250 & 900 & 8416 & 44630 & $<100$ & $<100$ & 3820 & 18190 \\
BpIII(UV-1570) & 14230 & 2840 & 140 & 33800 & 16570 & $<100$ & $<100$ & 2700 & 5900 \\
Bpp(21815) & $<100$ & $<100$ & $<100$ & $<100$ & $<100$ & 6110 & 3890 & 1180 & 6270 \\
Bpp(AK-167) & $<100$ & $<100$ & $<100$ & $<100$ & $<100$ & 4940 & 2930 & 1180 & 5040 \\
Bbs(L3) & 8330 & 3040 & $<100$ & 4030 & 8840 & 1790 & 1050 & 2890 & 16180 \\
Bbs(H-214) & 6680 & 2400 & 130 & 1150 & 8650 & 2200 & 1950 & 3290 & 274390 \\
E. coli & $<100$ & $<100$ & $<100$ & $<100$ & $<100$ & $<100$ & $<100$ & $<100$ & $<100$ \\
\hline \hline
\end{tabular}

* Antigens were used at $1 \mu \mathrm{g} \mathrm{ml}^{-1}(0 \cdot 1 \mu \mathrm{g}$ per well).

exception of BpI(18-323) (Fig. 1, lane 3). The gel patterns of the two LPS preparations from $B$. parapertussis showed a ladder-type arrangement of the bands of high molecular mass, and a single fast-migrating band of low molecular mass (Fig. 1, lanes 6 and 7). The latter band was similar in molecular mass to the $3.4 \mathrm{kDa}$ band of LPS from $B$. pertussis strains. Two LPS preparations from $B$. bronchiseptica, however, showed different gel patterns from each other. The LPS from Bbs(L3) showed two bands, of 5.1 and $3.5 \mathrm{kDa}$, respectively (Amano et al., 1988) (Fig. 1, lane 8), whereas that from $\mathrm{Bbs}(\mathrm{H}-214)$ was composed of faintly stained ladder bands and a single major band of low molecular mass (Fig. 1, lane 9).

\section{Antigenicity of LPS of Bordetella}

The antigenicity of LPS of Bordetella species was examined by agglutination assay and the ELISA, using hyperimmune antisera against whole cells of Bordetella species. Table 4 shows the antigenicity of LPS prepara- 

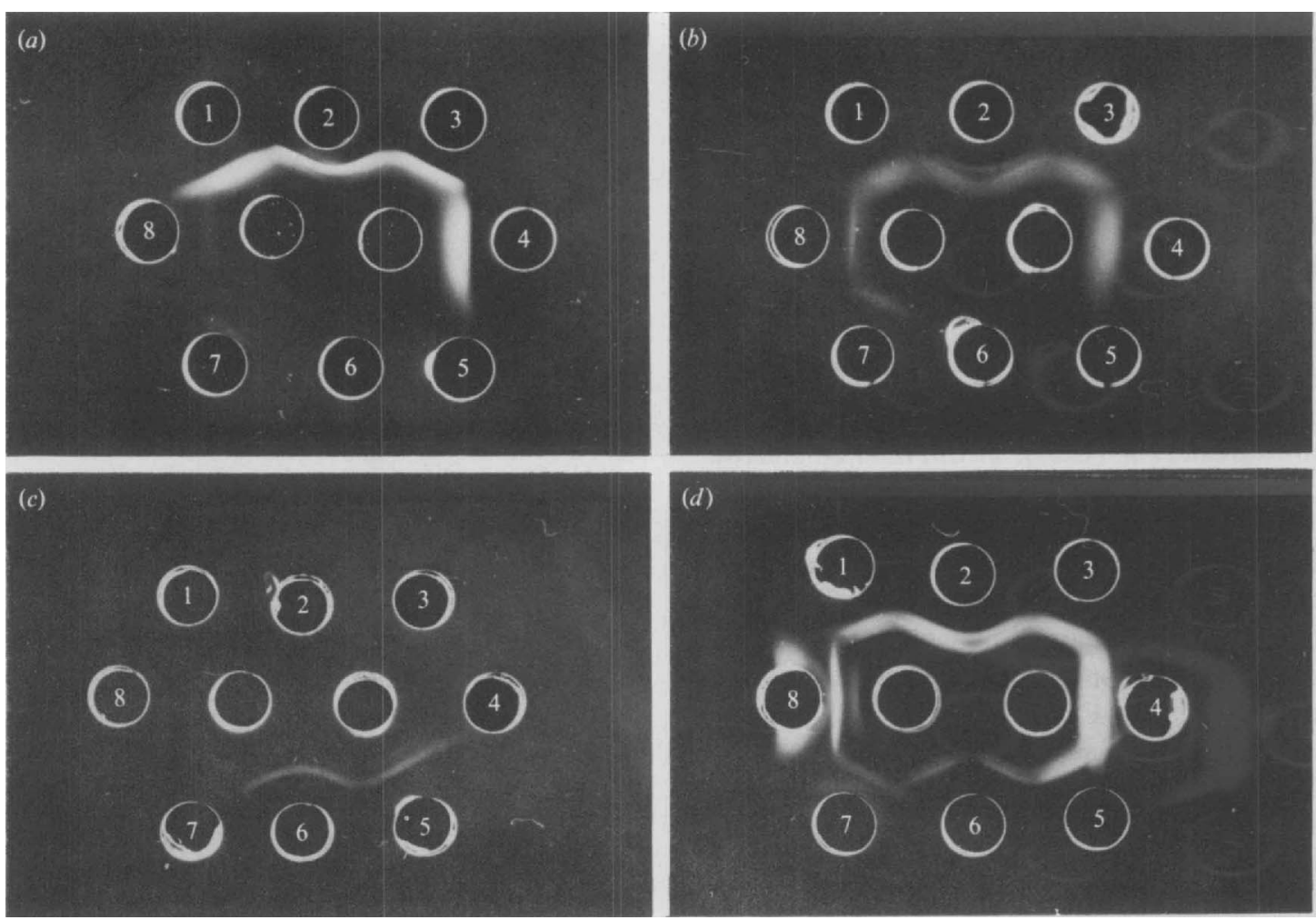

Fig. 2. Double immunodiffusion patterns of LPS preparations from Bordetella species. The centre wells contained sera against (a) whole cells of BpI(TOHAMA), (b) whole cells of BpIII(SAKAIRI), $(c)$ whole cells of Bpp(21815), and $(d)$ whole cells of Bbs(H-214), versus LPS from (1) BpI(TohaMA), (2) BpI(AK-168), (3) BpIII(saKaIRI), (4) BpIII(UV-1570), (5) Bpp(21815), (6) Bpp(AK-167), (7) Bbs(L3), and (8) $\mathrm{Bbs}(\mathrm{H}-214)$.

tions determined by ELISA. The antisera against $B$. pertussis phase I reacted with all the LPS preparations from Bordetella, except those from $B$. parapertussis; the anti-BpIII sera also reacted with the same LPS preparations. Anti-Bpp sera reacted with LPS from $B$. parapertussis and $B$. bronchiseptica, but the reactivity with $B$. bronchiseptica LPS was weak. The anti-Bbs sera reacted with all the Bordetella LPS preparations. These results indicate that the LPS of $B$. pertussis is similar in all strains regardless of the phase, and that it has a structure in common with LPS from $B$. bronchiseptica. The LPS from $B$. parapertussis were also similar to those from $B$. bronchiseptica, but different from those of $B$. pertussis. The LPS from $B$. bronchiseptica contained antigenic structures in common with the LPS from the other Bordetella species.

In an Ouchterlony immunodiffusion test (Fig. 2), antiBpI(TOHAMA) and anti-BpIII(SAKAIRI) sera reacted strongly with all the LPS preparations from $B$. pertussis and weakly with $B$. bronchiseptica, whereas the anti$B p p(21815)$ serum reacted with LPS from $B$. parapertussis and $B$. bronchiseptica. The anti-Bbs $(\mathrm{H}-214)$ serum reacted with all the Bordetella LPS preparations. These results confirmed the ELISA data. In the immunodiffusion test, multiple precipitin lines were formed between LPS and anti-Bordetella sera, especially with LPS from BpI(AK-168) and serum against whole cells of BpI(sAKAIRI) (Fig. $2 b$ ), and with LPS from $B$. bronchiseptica and serum against whole cells of $\mathrm{Bbs}(\mathrm{H}-214)$ (Fig. $2 d$ ). These multiple lines were possibly due to protein contamination.

\section{Discussion}

Szabo and his colleagues reported that $B$. pertussis LPS has two chemically different fractions (LeDur et al., 1980), containing KDO-P (Caroff et al., 1987; Chaby \& Szabo, 1975). They determined that the polysaccharide moiety of these LPS preparations was made up of a heptasaccharide, composed of glucose, $\mathrm{N}$-acetylglucosamine, glucuronic acid, $\mathrm{N}$-acetylgalactosaminuronic acid, heptose and KDO in a molar ratio of $1: 2: 1: 1: 1: 1$ (Moreau et al., 1984). Peppler (1984) reported the presence of LPS in B. bronchiseptica by SDS-PAGE using proteinase-K-treated whole cells, and $\mathrm{Li}$ et al. (1988) 
demonstrated LPS in B. parapertussis and B. bronchiseptica by SDS-PAGE using whole cells treated with pronase. In neither report was LPS isolated or the structure of LPS determined.

The chemical analysis in this study indicated that the various LPS preparations had components in common (GlcN, GlcN-P, heptose, neutral sugar, uronic acid, $\mathrm{KDO}$, phosphate and fatty acids) but in different molar ratios. By gas chromatography, the only neutral sugar found in LPS preparations from $B$. pertussis and $B$. bronchiseptica was heptose, while no neutral sugar was found in LPS from $B$. parapertussis strains. Contrary to the report of Moreau et al. (1984), we did not find glucose as a component of the polysaccharide moiety in $B$. pertussis LPS. The preparation of Moreau et al. (1984) may have been different from ours and this may account for the discrepancy. Chaby \& Szabo (1975) reported that the LPS of B. pertussis contained phosphorylated KDO (KDO-P) and this component did not give a positive thiobarbiturate reaction. Caroff et al: (1987) demonstrated that LPS from B. parapertussis and B. bronchiseptica were also thiobarbiturate negative, but after dephosphorylation these LPS preparations gave a positive reaction. Based on these reports, we used strong acid hydrolysis ( $2 \mathrm{M}-\mathrm{HCl}$ for $90 \mathrm{~min}$ ) to release $\mathrm{KDO}$ from LPS preparations for the quantitative analysis of KDO (Brade et al., 1983).

Peppler (1984) and Li et al. (1988) described the presence of two different LPS components in $B$. pertussis by immunoblotting using polyclonal and monoclonal antibodies, respectively. We also showed by SDS-PAGE two different molecular mass components in five LPS preparations from $B$. pertussis. These preparations contained smaller amounts of the fast-migrating band than of the slower-migrating band. Although we do not know the structural relationship between the two components, Li et al. (1988) suggested that the two components may be useful for the establishment of serogroups for Bordetella species. The chemical analyses, SDS-PAGE profile and immunological antigenicity indicated that the chemical structures of LPS from $B$. pertussis phases I and III are similar; the LPS from $B$. pertussis and $B$. bronchiseptica contain partial similarities and the LPS from $B$. parapertussis and $B$. bronchiseptica also contain partial common structures. The chemical and immunological structures of the LPS preparations from $B$. pertussis and $B$. parapertussis were completely different. Our data obtained by using polyclonal antibodies against whole cells of Bordetella confirmed the result of $\mathrm{Li}$ et al. (1988) that monoclonal antibody against $B$. pertussis cells reacted with LPS from $B$. pertussis and $B$. bronchiseptica but not with LPS from $B$. parapertussis. Thus, the LPS from $B$. bronchiseptica possess two different epitopes, one in common with the LPS from $B$. pertussis and the other in common with the LPS from $B$. parapertussis.

The authors wish to thank Dr John J. Munoz for reviewing the manuscript.

\section{References}

Amano, K. \& Williams, J. C. (1984). Chemical and immunological characterization of lipopolysaccharides from phase I and phase II Coxiella burnetii. Journal of Bacteriology 160, 994-1002.

amano, K., Williams, J. C., McCaul, T. F. \& Peacock, M. G. (1984). Biochemical and immunological properties of Coxiella burnetii cell wall and peptidoglycan-protein complex fractions. Journal of Bacteriology 160, 982-988

amano, K., Tamura, A., Ohashi, N., Urakami, H., Kaya, S. \& Fuxushi, K. (1987). Deficiency of peptidoglycan and lipopolysaccharide components in Rickettsia tsutsugamushi. Infection and Immunity 55, 2290-2292.

Amano, K., Mizushiri, S. \& Fukushi, K. (1988). Molecular weight determination of lipopolysaccharides from rough-type gram-negative bacteria by SDS-polyacrylamide gel electrophoresis. Japanese Journal of Bacteriology 43, 911-916.

Bergman, R. K. \& Munoz, J. J. (1977). Increased histamine sensitivity in mice after administration of endotoxins. Infection and Immunity 15, 72-77.

Brade, H., Galanos, C. \& Luderitz, O. (1983). Differential determination of the 3-deoxy-D-manno-octulosonic acid residues in lipopolysaccharides of Salmonella minnesota rough mutant. European Journal of Biochemistry 131, 195-200.

Caroff, M., Lebbar, S. \& Sżabo, L. (1987). Do endotoxins devoid of 3deoxy-D-manno-2-octulosonic acid exist? Biochemical and Biophysical Research Communications 143, 845-847.

ChabY, R. \& SzABO, L. (1975), 3-Deoxy-2-octulosonic acid 5phosphate: a component of the endotoxin of Bordetella pertussis. European Journal of Biochemistry 59, 277-280.

Dubois, M., Gilles, K. A., Hamilton, J. K., Rebers, P. A. \& Smith, F. (1956). Colorimetric method for determination of sugars and related substances. Analytical Chemistry 28, 350-356.

Finger, H., Heymer, B., Hof, H., Rietschel, E. \& Schleifer, K. H. (1976). Über Struktur und biologische Aktivität von Bordetella pertussis Endotoxin. Zentralblatt für Bakteriologie, Mikrobiologie und Hygiene (Abteilung I, Originale A) 235, 56-64.

HitchCock, P. J., Leive, L., Makela, P. H., Rietschel, E. T., StritTMATTER, W. \& MORRISON, D. C. (1986). Lipopolysaccharide nomenclature - past, present, and future. Journal of Bacteriology 166 , 699-705.

Karkhanis, Y. D., Zeltner, J. Y., Jackson, J. J. \& Carlo, D. J. (1978). A new and improved microassay to determine 2-keto-3deoxyoctonate in lipopolysaccharide of gram-negative bacteria. Analytical Biochemistry 85, 595-601.

Kasai, N., Arata, S., Mashimo, J., OKuda, K., Aimara, Y., Kotani, S., Takada, H., Shiba, T., Kusumoto, S., Imoto, M., Yoshimura, H. \& Shimamoto, T. (1986). Synthetic Salmonella-type lipid A antigen with high serological specificity. Infection and Immunity $\mathbf{5 1}$, 43-48.

Kurokawa, M., Ishida, S., Asakawa, S. \& Iwasa, S. (1978). Attempt at analysis of toxicity of pertussis vaccine. III. Effects of endotoxin on leukocytosis in mice due to lymphocytosis-promoting factor and reference preparations for determination of lymphocytosis-promoting factor. Japanese Journal of Medical Science and Biology 31; 91 103.

LAEMmLI, U. K. (1970). Cleavage of structural proteins during the assembly of the head of bacteriophage T4. Nature, London 227, 680685 .

LeDur, A., Chaby, R. \& SzABo, L. (1980). Isolation of two protein-free and chemically different lipopolysaccharides from Bordetella pertussis phenol-extracted endotoxin. Journal of Bacteriology 143, 78-88. 
Li, Z. M., Cowell, J. L., Brennan, M. J., Burns, D. L. \& Manclark, C. R. (1988). Agglutinating monoclonal antibodies that specifically recognize lipopolysaccharide A of Bordetella pertussis. Infection and Immunity 56, 699-702.

LOWRY, O. H., ROBERTS, N. R., LEINER, K. Y., WU, M.-L. \& FARR, A. L. (1954). The quantitative histochemistry of brain. I. Chemical methods. Journal of Biological Chemistry 207, 1-17.

MacLenNan, A. P. (1960). Specific lipopolysaccharides of Bordetella. Biochemical Journal 74, 398-409.

Moreau, M., Chaby, R. \& Szabo, L. (1984). Structure of the terminal reducing heptasaccharide of polysaccharide 1 isolated from the Bordetella pertussis endotoxin. Journal of Bacteriology 159, 611617.

Nakase, Y., Tateisi, M., Sekiya, K. \& Kasuga, T. (1970). Chemical and biological properties of the purified $\mathrm{O}$ antigen of Bordetella pertussis. Japanese Journal of Microbiology 14, i-8.

Nichols, W. S. \& Nakamura, R. N. (1980). Agglutination and agglutination inhibition assays. In Manual of Clinical Immunologv, pp. 15-22. Edited by N. R. Rose \& H. Friedman. Washington, DC: American Society for Microbiology.
OSBORN, M. J. (1963). Studies on the gram-negative cell wall. I. Evidence for the role of 2-keto-3-deoxyoctonate in the lipopolysaccharide of Salmonella typhimurium. Proceedings of the National Academy of Sciences of the United States of America 50, 499-506.

OUCHTERLONY, O. (1958). Diffusion-in-gel methods for immunological analysis. Progress in Allergy 5, 1-78.

Peppler, M. S. (1984). Two physically and serologically distinct lipopolysaccharide profiles in strains of Bordetella pertussis and their phenotype variants. Infection and Immunity 43, 224-232.

Stainer, D. W. \& SCHOLTE, M. J. (1971). A simple chemically defined medium for the production of phase I Bordetella pertussis. Journal of General Microbiology 63, 211-220.

Watanabe, M., Haraguchl, Y., Gonda, T., Aoyama, T., Ozawa, H., Murase, Y., Iwata, T., Iwata, S. \& Kusano, S. (1987). Serotype and drug sensitivity of Bordetella pertussis and Bordetella parapertussis isolated from 1975 to 1985 in Japan. Japanese Journal of Infectious Diseases 61, 79-86.

WestPhal, O. \& JANN, K. (1965). Bacterial lipopolysaccharides. Extraction with phenol-water and further application of the procedure. Methods in Carbohydrate Chemistry 5, 83-91 